\title{
Health Technology performance Assessment: Real-World Evidence for Public Healthcare Sustainability
}

Guerra Júnior $A^{1,2}$, Lemos $\mathrm{L}^{1,3}$, Godman $\mathrm{B}^{4,5}$, Bennie $\mathrm{M}^{4}$, Osorio de Castro $\mathrm{C}^{6}$, Alvares $\mathrm{J}^{1,2}$, Heaney $\mathrm{A}^{7}$, Vassallo $C^{8}$, Wettermark $B^{5,9,10}$, Benguria-Arrate $G^{11}$, Gutiérrez-Ibarluzea ${ }^{11}$, Santos V $C^{12}$, Petramale $\mathrm{C}^{12}$, Acurcio $\mathrm{F}^{1,2}$

${ }^{1}$ SUS Collaborating Centre for Technology and Excellence in Health, Universidade Federal de Minas Gerais; Belo Horizonte, Brazil

${ }^{2}$ Department of Social Pharmacy, School of Pharmacy, Universidade Federal de Minas Gerais, Belo Horizonte, Brazil

${ }^{3}$ Post-Graduation Program in Public Health, School of Medicine, Universidade Federal de Minas Gerais

${ }^{4}$ Strathclyde Institute of Pharmacy and Biomedical Sciences, Strathclyde University, Glasgow, Scotland

${ }^{5}$ Division of Clinical Pharmacology, Karolinska Institutet, Karolinska University Hospital Huddinge, Stockholm, Sweden

${ }^{6}$ Sergio Arouca National School of Public Health, Fundação Oswaldo Cruz, Rio de Janerio, Brazil

${ }^{7}$ National Prescribing Service Medicinewise, Australia

${ }^{8}$ Facultad de Ciencias Médicas, Universidad Nacional del Litoral, Sante Fe, Argentina

${ }^{9}$ Public Healthcare Services Committee, Department of Healthcare Development, Stockholm County Council, Stockholm, Sweden

${ }^{10}$ Department of Medicine Solna, Clinical Epidemiology/Clinical pharmacology, Karolinska Institutet and Karolinska University Hospital, Stockholm, Sweden

${ }^{11}$ Osteba, Basque Office for HTA, Ministry for Health Basque Government, Bilbao, Spain

${ }^{12}$ Department of Management and Incorporation of Technologies, Brazilian Ministry of Health, Brazilia, Brazil

Corresponding author: Lívia Lovato Pires de Lemos

Address: Faculdade de Farmácia da Universidade Federal de Minas Gerais, sala 1042. Av.

Presidente Antônio Carlos, 6627 - Campus Pampulha - CEP 31270-901, Belo Horizonte - MG - Brasil +553134096394 
(Accepted for publication: International Journal of Technology Assessment in Health Care)

\section{Abstract}

Objective: Health technology financing is often based on randomized controlled trials (RCTs), which are often the same ones used for licensing. Since they are designed to show the best possible results with typically Phase III studies conducted under ideal and highly controlled conditions to seek high internal validity and maximize the chance of demonstrating clinical benefit, they often do not reflect likely effectiveness in routine clinical care. Consequently, it is not surprising that technologies do not always perform in real life in the same way as controlled conditions. Since financing (and price paid) decisions can be made with overestimated results, health authorities need to ask whether health systems achieve the results they expect when they choose to pay for a technology. The optimal way to answer this question is to assess the performance of financed technologies in real world settings. Health technology performance assessment (HTpA) refers to the systematic evaluation of the properties, effects, and/or impact of a health intervention or health technology in the real world to provide information for investment/ disinvestment decisions and clinical guideline updates. The objective is to describe the development and principal aspects of the Guideline for HTpA commissioned by the Brazilian Ministry of Health. Method: Extensive literature review, refinement with experts across countries and public consultation. Results: A comprehensive guideline was developed, which has been adopted by the Brazilian government. Conclusion: We believe the guideline, with its particular focus on disinvestment, along with the creation of a specific program for HTpA, will allow the institutionalization and continuous improvement of the scientific methods to use real world evidence to optimize available resources not only in Brazil but across countries.

Keywords: Technology Assessment, Biomedical; Observational studies; Health policy; Health Information Systems

Policy implications: Real-world evidence is emerging as an important tool to aid decision-making regarding health technology financing. Over the last decade, countries have developed health and/ or administrative registries capable of providing quality data for assessing health results in real life. At the same time, budgetary constraints and the pressure to finance emerging high-priced technologies are making it inevitable for health authorities to start assessing whether patients and society are getting the results from financed technologies agreed upon during investment decisions. This paper presents the concept of Health Technology performance Assessment and the development of a guideline, commissioned by the Brazilian Ministry of Health, to implement such activity. We believe it is the first guideline to formally incorporate the use of real-world evidence for updating clinical guidelines, price renegotiation and disinvestment decisions. 


\section{INTRODUCTION}

In many developed and developing countries, decision-making regarding health technology funding is based on results from Health Technology Assessments (HTA) $(1,2)$. These assessments often include the same studies conducted for licensing - the randomized clinical trials (RCTs), which are considered to provide "gold standard" evidence (3). However RCTs, especially those conducted by the manufacturer, have important limitations. Since they are designed to show the best possible result for the new technology, i.e. typically Phase III studies are conducted under ideal and highly controlled conditions to seek high internal validity and maximize the chance of demonstrating clinical benefit (4), they frequently select patients more likely to present the best response, and do sometimes use placebo as a control even when standard treatment already exists (5). As a result, it is expected that technologies do not always perform in real-life in the same way as they performed in controlled conditions. As consequence, RCTs can fail to offer evidence of the effectiveness of technologies in routine clinical care especially as patients may well be older and more co-morbid than those contained in RCTs (6).

Beyond concerns with RCTs, inherent limitations in a number of studies used for HTA decisions include the use of surrogate measures and secondary outcomes, using grouped outcome measures, using a single pivotal trial or over-powering trials, all of which may enhance the efficacy and/ or understate the adverse effects of technologies. Concerns with surrogate markers have been highlighted in a number of situations (7-10). It has also been shown that in the USA single pivotal trials gave support to almost a third of new drug approvals from 2005-2012. More than two thirds of new drugs were also approved on the basis of studies lasting six months or less $(11,12)$. Adding to this, despite ethical and statutory mandates, lack of transparency and publication bias are still major concerns. For instance, it has been shown that less than $50 \%$ of RCTs are published in a five-year window since registering them Onto ClinicalTrials.gov (13).

Furthermore, scientific methods used to assess whether or not it is worth paying for new higher priced technologies are typically based on evidence provided by the manufacturer and tend to favor the perception that it is, indeed, worth paying a premium price. The consequence is the potential of ever increasing healthcare expenditure as each newly reimbursed technology is used to establish new cost-effectiveness threshold levels (14). This is a concern as a number of countries are struggling to fund new higher priced medicines, which is not in the best interest of any key stakeholder group (4). In addition, most countries that use economic analyses for reimbursement decisions are still reluctant to set economic threshold levels (1). Authors have argued that by defining a threshold, health authorities are setting and disseminating a price ceiling to which manufacturers will seek to reach instead of negotiating lower prices (15). This has consequence of pushing up prices and increasing the burden on public health budgets, as seen for instance with new cancer medicines and those for orphan diseases $(16,17)$. Even in cases where health authorities choose to set a threshold value, there are debates in literature that lower thresholds should be established for new medicines in prevalent conditions (15) as the current 
threshold levels are seen as too high (18), especially with little empiric basis for establishing these values.

Adding to this, after new technologies are incorporated into reimbursement lists, there is often limited further evaluation of their real value unless they are part of managed entry agreements (19). This is a concern both in terms of opportunity costs as well as patient care. For instance, meta-analyses and independent cohort studies have continued to show no difference in effectiveness between isophane insulin, rDNA insulins and long acting insulins despite considerable differences in prices (20). In other case, studies have shown surprisingly differing results in real life in the case of medicines for transplantation (21). On the other hand despite early concerns, long-term cohort studies have demonstrated the effectiveness and safety of TNF alpha inhibitors in patients with immune diseases although the effectiveness of treatments in real-life may be different from those seen in randomized clinical trials (22). These situations raise the question of whether health systems actually obtain the results they are expecting when they choose to pay for new technologies.

In light of this, we believe new approaches are needed to continually re-assess technologies and evaluate their performance in the real world given continuing pressure on resources. In this article we describe the development of the Guideline for Health Technology performance Assessment produced by the SUS Collaborating Centre for Technology Assessment and Excellence in Health (CCATES) in collaboration with many international experts and the support of the Pan-American Health Organization (PAHO) and the Department of Management and Incorporation of Technologies from Brazilian Ministry of Health. The objective of the Guideline was to stablish the monitoring of funded technologies using real world evidence to assess their performance and update clinical guidelines. The main focus will be on disinvestment as this is a growing area of interest given pressure on resources. We hope this will be of interest not only in Brazil but wider.

\section{HEALTH TECHNOLOGY PERFORMANCE ASSESSMENT}

Health technology performance assessment (HTpA) refers to the systematic evaluation of properties, effects, and/or impacts of a health intervention or health technology in the real world. It provides information to health systems to support the update of clinical guidelines and/ or continued reimbursement by contrasting health and safety results in the whole population with initial RCT information. The HTPA matches real life results with technology values. In the process of evidence based decisions, $\mathrm{HTpA}$ is undertaken after a positive reimbursement/public provision decision, leading to clinical guideline updates (Figure 1). In Brazil, the inclusion of new technologies in updated clinical guidelines is essential for their reimbursement within the public health system (SUS); otherwise they are not reimbursed $(20,23)$. 
Figure 1. Process of evidence-based decisions. Health Technology performance Assessment is the evaluation of the results of financed technologies in real-world settings

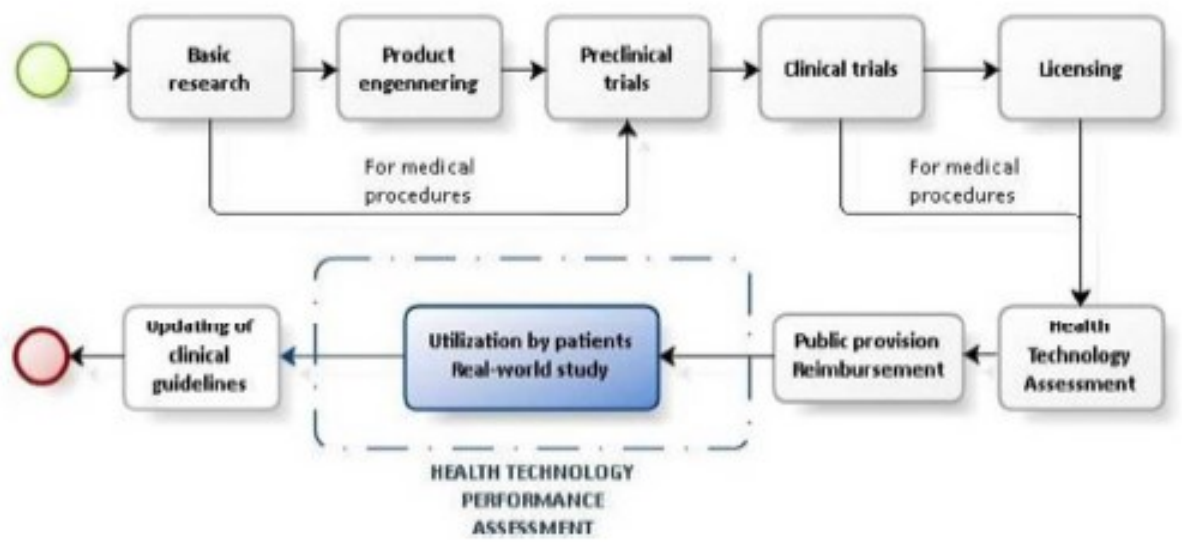

HTpA may indicate the need to disinvest in one or more of the four modalities as shown below (adapted from Daniels et al. (24):

- Full delisting - Delisting of the technology. It is the most difficult modality to implement and has great potential for unmanaged substitution;

- Restriction - The provision of the technology will be restricted to groups or subgroups of users, with strictly criteria for its use. It may be seen as discriminatory. It can be reversed or enlarged as required;

- Retraction - The technology will be supplied in a smaller amount to each individual, e.g. 1 mammogram/ year instead of 2. Potentially more acceptable than full delisting;

- Substitution - The currently offered technology will be replaced by a cost-effective alternative, ensuring equivalent treatment/service.

3. Price renegotiations may be applied with restrictions to defined patient populations to help target resources to the patient populations of highest value. This may be preferable to not reimbursing patented medicines in a class once generics become available in that class. DEVELOPMENT OF THE GUIDELINE

A review was conducted to identify necessary aspects to be addressed in the guideline. Scientific literature and HTA Agencies/Government were scanned for eligible reports. Key-principles for HTpA were adapted from HTA principles (50), which helped orientate the development of the first draft of the guideline. Similar to HTA, the performance assessment must be current and timely, its scope should be explicit and relevant, and the process must be transparent and actively involve interested stakeholders. When only a few technologies are evaluated, there must be a clear process of selection of these technologies in order to avoid distortions in investment decisions and to ensure transparency. HTpA should be conducted with appropriate and rigorous methods for 
assessing costs and benefits, in order to generate confidence among key stakeholders including the general public in its conclusions. Even though HTpA reports must be designed and/ or destined to health authority managers with clear and objective recommendations, it is important to develop strategies to disclose the study and its conclusions to the different social actors.

\section{RESULTS}

\subsection{Development of the first version of the guideline using a "snowball" technique.}

Public health researchers, health managers and policymakers were invited to contribute via email and in meetings held by CCATES to help develop the guideline. After receiving contributions to the draft, the first version of the guideline was developed. One of the proposals to the draft was the implementation of a program to institutionalize the continuous assessment of incorporated health technologies. The implementation of such a program would serve as a landmark for the possibility of disinvestment for all existing technologies and for all technologies candidates for potential incorporation.

The guideline was divided in eight sections: (i) Introduction; (ii) Steps of disinvestment process (iv vii); (iii) Permanent program for assessing the performance of technologies; (iv) Identification of potential technologies for disinvestment; (v) Prioritization; (vi) Health Technology Reassessment; (vii) Implementation of disinvestment decision; and (viii) Final Remarks. This version was entitled "Disinvestment Guideline Proposal".

The proposed activities for the permanent program for assessing the performance of technologies were:

(i) the continuous monitoring of the effectiveness of financed technologies;

(ii) the establishment of a legal framework and of organizational mechanisms to enable and facilitate technology disinvestment where pertinent;

(iii) the active search for candidate technologies for disinvestment and;

(iv) monitoring the impact of the disinvestment.

We proposed that the health technology indication for performance assessment could arise from within health systems or from society. To be eligible for HTpA, a reimbursed/provided technology must comply with at least one of the requirements as specified in Table 1 
Table 1. Criteria for identification of financed health technologies for Health Technology performance Assessment

\begin{tabular}{|c|c|}
\hline \multicolumn{2}{|r|}{ IDENTIFICATION OF HEALTH TECHNOLOGIES } \\
\hline Criteria & Possible indicatives \\
\hline \multirow{3}{*}{ Safety } & $\begin{array}{l}\text { There is unacceptable potential safety risk for users, society or the } \\
\text { environment related to the use of technology; }\end{array}$ \\
\hline & $\begin{array}{l}\text { There is evidence demonstrating that the technology generates } \\
\text { unacceptable risk-benefit concerns; }\end{array}$ \\
\hline & $\begin{array}{l}\text { There is evidence showing that new technologies get the same results, } \\
\text { but record significantly higher levels of safety. }\end{array}$ \\
\hline \multirow{4}{*}{ Effectiveness } & Absence or low evidence of efficacy and effectiveness of the technology; \\
\hline & $\begin{array}{l}\text { There is evidence showing inefficacy and ineffectiveness of the } \\
\text { technology in one or more indications; }\end{array}$ \\
\hline & $\begin{array}{l}\text { There is evidence showing that new/other technologies with the same } \\
\text { results have better cost-effectiveness ratio; }\end{array}$ \\
\hline & $\begin{array}{l}\text { There is evidence showing that new technologies, with the same price, } \\
\text { record higher levels of efficacy/effectiveness. }\end{array}$ \\
\hline \multirow{3}{*}{ Cost } & $\begin{array}{l}\text { There is evidence demonstrating that the monetary value of the } \\
\text { technology is not translated in the proposed benefit; }\end{array}$ \\
\hline & $\begin{array}{l}\text { There is evidence showing that there are other technologies that provide } \\
\text { the same results with lower prices/ costs; }\end{array}$ \\
\hline & $\begin{array}{l}\text { There is no reduction of the technology price over time, showing to be } \\
\text { non-competitive with other cheaper technologies that guarantee the } \\
\text { same results. }\end{array}$ \\
\hline Cost- effectiveness & $\begin{array}{l}\text { There is evidence proving that a competitive technology presents a } \\
\text { better cost-effectiveness ratio than that available. }\end{array}$ \\
\hline Disuse & $\begin{array}{l}\text { There is evidence showing that the technology is no longer being used } \\
\text { by the users of the health system. }\end{array}$ \\
\hline Inappropriate use & $\begin{array}{l}\text { There is evidence showing that the technology is being improperly used. } \\
\text { For example, in excess, or when it is used by groups for which the } \\
\text { technology is not intended to. }\end{array}$ \\
\hline Logistics & $\begin{array}{l}\text { There is evidence showing that a competitive technology, with the same } \\
\text { results, needs a simplified logistics plan, with proven lower costs, } \\
\text { showing to be more suitable to the conditions of use. }\end{array}$ \\
\hline \multirow[t]{2}{*}{ Availability } & $\begin{array}{l}\text { The unavailability of the technology in the market, due to, for example, } \\
\text { deviation of the quality during production, the non-renewal of the } \\
\text { registration of marketing or the interruption of production. }\end{array}$ \\
\hline & $\begin{array}{l}\text { The unavailability of essential material or accessory for the proper } \\
\text { functioning of the technology. }\end{array}$ \\
\hline \multirow{3}{*}{ Acceptability } & $\begin{array}{l}\text { There is evidence showing that the technology produces important } \\
\text { discomfort/pain, undesirable side effect that causes the interruption of } \\
\text { treatment; }\end{array}$ \\
\hline & $\begin{array}{l}\text { There is evidence showing that the technology produces negative } \\
\text { repercussions because it is considered "invasive"; }\end{array}$ \\
\hline & $\begin{array}{l}\text { There is evidence showing that the technology leads to poor quality of } \\
\text { life of the users; }\end{array}$ \\
\hline
\end{tabular}




\begin{tabular}{|l|l|}
\hline & $\begin{array}{l}\text { There is evidence showing that the technology records relevant levels of } \\
\text { nonadherence. }\end{array}$ \\
\hline Adequacy & $\begin{array}{l}\text { There is evidence showing that the technology is considered by health } \\
\text { professionals as not relevant for clinical practice. }\end{array}$ \\
\hline Contraindications & $\begin{array}{l}\text { There is evidence showing that after the incorporation, the technology } \\
\text { has relevant contraindication that endangers or limits the use by } \\
\text { patients in clinical practice. }\end{array}$ \\
\hline
\end{tabular}

For prioritization, we used "Multicriteria Decision Analysis" incorporating Value Measurement Models, using criteria adapted from those proposed by Elshaug et al. (2009) (26) and those used by the Canadian Agency for Drugs and Technologies in Health (CADTH) for prioritizing technologies for evaluation in the context of incorporation (27).

The HTpA section addresses the performance assessment modalities (full withdrawal/full delisting; restriction; retraction and substitution); price renegotiation; the HTpA process itself; and the elaboration of recommendations to health managers. It also addresses the need to indicate in the HTpA report a period of time sufficient to implement the decision - the transition period.

The Implementation of any disinvestment decision resulting from the performance assessment section should address the organizational implications to be taken into account and overcome by health manages. This includes the necessity to redistribute, hire and train personnel and the necessity to implement reverse logistics measures to collect any remaining disinvested products, i.e. medicines, medical devices, etc. In addition, decisions may address the necessity to update clinical protocols and to produce different versions of the same protocol to reach different stakeholder groups, e.g. health professionals, health managers, politicians and patients.

The strategies for the dissemination of any decision should focus on the main social actors involved in the provision of the technology. All media should aim at transparency explaining the decision, and there should be clear explanations of the causes and consequences of any subsequent disinvestment decision to ensure full understanding of those who provide and use the technology, as well as to prevent the occurrence of unmanaged substitution and any judicial demands. Judicial demands are particularly prevalent in Brazil as seen with insulin glargine (20). Suggested strategies to address this include academic detailing, production and dissemination of videos and bulletins, and the creation of a direct communication channel to address potential doubters.

\subsection{Development of the second version of the guideline after the panel of experts to discuss key points and clinical cases to improve the document.}

In November 2015, an International Panel on Disinvestment was held at UFMG. This includes representatives from the Brazilian Ministry of Health; PAHO; the University of Strathclyde, UK; Karolinska Institute, Stockholm, Sweden and Stockholm County Council, Sweden; OSTEBA (Basque HTA), Fondo Nacional de Recursos (Uruguay); National Prescribing Service (Australia), and Universidad Nacional del Litoral (Argentina) to review the first version of the guideline. 
As basis for debate, in small group sessions, participants were invited to assess two performance assessment case studies, one focused in specialized care, i.e. evidence of the comparative effectiveness of beta interferon $1 \mathrm{~A} 6,000,000 \mathrm{IU}(30 \mu \mathrm{g})$ for multiple sclerosis, and the other in primary care regarding insulin analogue glargine. Both cases were accompanied by real-life evidence of effectiveness.

The most important decision arrived from the panel was to change the focus of the guideline from disinvestment to technology monitoring and clinical guideline update. The first discussion by the panelists concerned the term "disinvestment", which was considered to have a negative tone, and to be frequently associated with a 'loss of rights' and treatment denial, and not automatically associated with opportunity costs. In addition, as shown previously in the first version, technologies need to be continuously evaluated after financing decisions - this action was summarized under the term Health Technology performance Assessment.

Another important decision was to explicitly indicate to key stakeholder groups that continuous funding of a given technology is conditional on the beneficial results in real life, and this is a valid statement for technologies yet to be financed. Another relevant aspect that was later included in the guideline was the need for horizon-scanning programs to work closely with programs for assessing the performance of technologies in routine clinical care in order to identify key potential areas for disinvestment and avoid unnecessary evaluations.

In the updated version, two different overlapping flow diagrams were proposed, one for technologies not yet financed, and one for already financed ones (Figure 2). For already financed technologies, prioritization criteria were updated to include the rate of launching of new technologies - technologies from fast evolving areas may be prioritized since there may be a greater chance for substitution (Table 2). It is noteworthy that older technologies can sometimes have worse evidence as seen in the review of older medicines that had been superseded by newer more effective medicines in France (28). However, this may not always be the case as seen with tacrolimus versus cyclosporine and insulin glargine versus NPH insulins in Brazil $(20,21)$. Overall though, older funded technologies may be prioritized for HTpA to assess their continued funding. In addition, after the institutionalization of HTpA, not all technologies incorporated would be a priority for assessment. Technologies with high cost per treatment or high unitary cost, recently licensed technologies, and technologies/treatments considered groundbreaking may be prioritized for HTpA. Examples shaping utilization and funding including real world studies with the anti-TNF alphas for rheumatoid arthritis where fears of increased rates of cancer and infection have not been realized in practice (22) and the WOSCOPS study in Scotland where 20 year follow-up of statin therapy for 5 years is associated with improved survival and a substantial reduction in cardiovascular outcomes, supporting the wider adoption of primary prevention approaches (29). 
Figure 2. Flow diagrams for HTpA implementation. For financed technologies, HTpA may be suggested by any member of society - patients, health professionals, medical society, industry, etc. For technologies yet to be financed, appointment for HTpA may be assessed during or right after incorporation

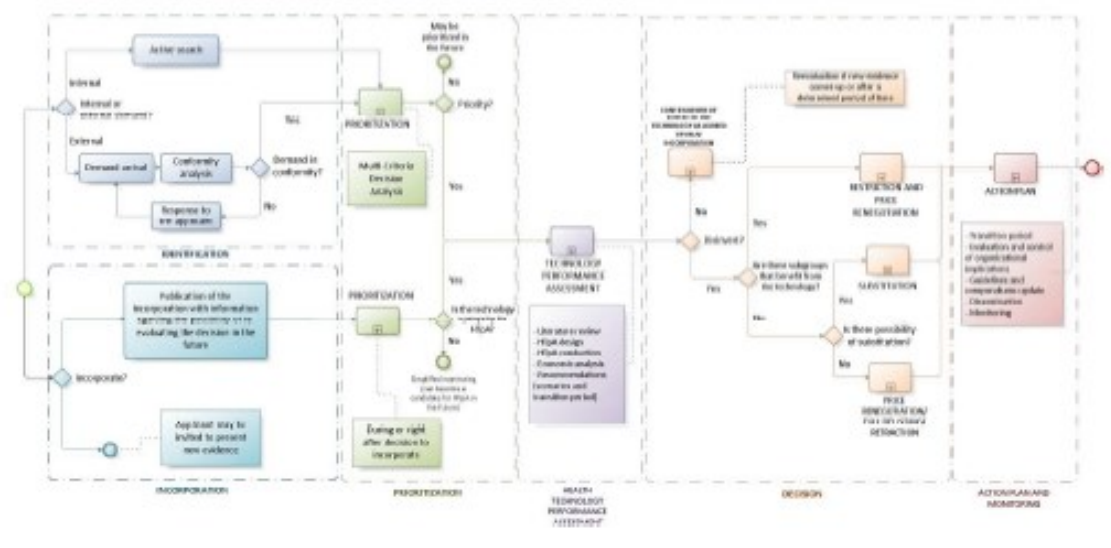

Table 2. Criteria for prioritization of financed health technology for HTpA

\begin{tabular}{|l|l|}
\hline \multicolumn{1}{|c|}{ Criteria } & \multicolumn{1}{c|}{ PRIORITIZATION } \\
\hline Safety issue & $\begin{array}{l}\text { Among the identified technologies, the ones related to health risks } \\
\text { should be prioritized }\end{array}$ \\
\hline Cost of service & $\begin{array}{l}\text { High cost per procedure, high cost due to the volume, or an aggregate } \\
\text { measure of both }\end{array}$ \\
\hline Probable impacts & $\begin{array}{l}\text { Related to health: e.g., gross estimate of quality-adjusted life year; } \\
\text { Related to costs: e.g., gross estimated of savings per patient; release of } \\
\text { additional resources, etc; Overall assessment of the maintenance of } \\
\text { equity in care, if the financing of health technology is modified (e.g., } \\
\text { access for subgroups of patients) }\end{array}$ \\
\hline $\begin{array}{l}\text { Cost-effective } \\
\text { alternative }\end{array}$ & $\begin{array}{l}\text { Priority should be given to technologies for which there are cheaper } \\
\text { alternatives with equivalent or better results }\end{array}$ \\
\hline Burden of disease & $\begin{array}{l}\text { Conditions associated with low disability or morbidity or low mortality } \\
\text { rates (excluding orphan diseases) can influence the prioritization of } \\
\text { different health conditions with high disability / morbidity or mortality. } \\
\text { Low burden conditions may reduce the potential for dispute; high } \\
\text { burden diseases can represent a greater scope for reinvestment / } \\
\text { reallocation of resources }\end{array}$ \\
\hline $\begin{array}{l}\text { Sufficient evidence } \\
\text { available for } \\
\text { decision }\end{array}$ & $\begin{array}{l}\text { Rigorous assessment requires robust evidence. Typically the evidence is } \\
\text { not 100\% conclusive, but they must be suitable to be useful in decision } \\
\text { making }\end{array}$ \\
\hline
\end{tabular}




\begin{tabular}{|l|l|}
\hline $\begin{array}{l}\text { Possibility to } \\
\text { generate evidence } \\
\text { for decision-making }\end{array}$ & $\begin{array}{l}\text { Time and budget possibility of conducting a study to support decision } \\
\text { making when there is little evidence available }\end{array}$ \\
\hline Futility & $\begin{array}{l}\text { An intervention that probably does not result in "significant survival" or } \\
\text { benefit can be prioritized }\end{array}$ \\
\hline $\begin{array}{l}\text { Possible political } \\
\text { impact }\end{array}$ & $\begin{array}{l}\text { Interventions in areas where there is political engagement should be } \\
\text { carefully evaluated, because this can be considered more or less priority } \\
\text { depending on the political moment }\end{array}$ \\
\hline $\begin{array}{l}\text { Rate of launch of } \\
\text { new technologies }\end{array}$ & $\begin{array}{l}\text { Technologies used for diseases that are the focus of scientific and } \\
\text { industrial interest should be prioritized. Often new technologies are } \\
\text { launched in the market (greater possibility of replacement technology) }\end{array}$ \\
\hline
\end{tabular}

Adapted from: Elshaug et al. (2009) (26) and Husereau et al. (27)

Technologies prioritized to HTpA will be evaluated using real-world evidence and incorporating resource utilization data in view of potential concerns. As part of this, it is recommended that a permanent program be established for monitoring the clinical effectiveness and the quality of use of medicines, procedures and equipment in Brazil in routine clinical care. It is responsibility of the program's staff to coordinate horizon scanning activities, receive external requests and for prioritization of activities. The design and conduct of any HTPA studies may be undertaken in cooperation with academic units taking into account any conflicts of interest. Society involvement in all stages of HTpA is highly recommended, both because HTpA includes the collection of outcomes from patients in real life and societal participation enhances the acceptability of disinvestment activities.

\subsection{Presentation and debate in the National Commission for Health Technology Incorporation (CONITEC/Brazil) and public consultation via online form in CONITEC/Brazil}

After presenting the Guideline to the plenary of CONITEC/Brazil, the proposal was submitted to public consultation in March 2016. A total of 89 comments were received through the online form in the CONITEC/Brazil website. Most of the contributors were from pharmaceutical companies. The author's answers for the key points raised by contributors were:

- Appropriateness of the guideline for technologies for rare diseases

For rare diseases, the HTpA would be guided by effectiveness and safety results. It is noteworthy that in the absence of therapeutic alternative technologies for rare diseases, they probably would not be candidates for full delisting. However, these technologies should be evaluated for price adjustments where this is a concern as well as the identification of patient sub-groups who may truly benefit from the technology. This follows the experiences in the Netherlands with enzyme replacement therapy for Fabry and Pompe disease where pressure was exerted on the Ministry of Health to fund these technologies up to $€ 15$ million/ QALY despite coverage with evidence schemes showing limited benefit in clinical practice (17). 
- Health professionals and patients participation in HTpA

The participation of patients and health professionals is fundamental to HTpA. We believe that public consultations on the recommendations are very important and have the power to change or improve decisions regarding disinvestment and reinvestment. As indicated in the Guideline, it is recommended that public consultation mechanisms are adopted at all stages of the process. This includes patient participation in HTpA studies.

- Medical advocates

The adoption of clinical practices based on best evidence produced without conflicts of interest ensures professionals they are providing their patients with the best possible care within available resources. The HTpA process will present the best evidence for the updating of clinical guidelines, regardless of the recommendation to disinvest or not.

"Passive disinvestment" as discussed in the public consultation process, assumes that all medical professionals have access to updated scientific evidence from reputable sources and act upon it. However, this does not always happen in practice as seen by the continued use of tacrolimus for kidney transplantation despite real world evidence supporting greater effectiveness with cyclosporine at substantially higher costs (21). . Moreover, physician prescribing can be influenced by "success bias" in which prescribers take note of their successful results ignoring cases of nonsuccess, which may be due to patients not returning, giving the impression that the adopted therapeutic approach was optimal when, in fact, it was not.

- Companies participation in HTpA

During or soon after incorporation, manufacturers may submit a simplified methodological approach for assessing the performance of the technology in routine clinical practice using outcome parameters adopted by the submitted cost-effectiveness analysis. It is noteworthy that the conduction of HTPA in the country strengthens local and regional company medical and pharmacoeconomic divisions.

- Substitution modality could make the process vicious

$\mathrm{HTpA}$ of technologies incorporated before the adoption of this guideline, and those not prioritized during the incorporation process, will occur after indication (demand) and prioritization (Table 1). To indicate a technology, or demand a HTpA, the applicant must present at least one study showing compliance with at least one of the criteria shown in Table 2. We believe that the institutionalization of HTPA will increase the competitiveness of companies.

- $\quad$ Financing of HTpA studies

There is room in the national health research agenda for HTpA activities financed by the Ministry of Health in Brazil following directives from the Federal Constitution. In addition, new acquisition arrangements can be established in which a part of the price paid for the technology is used to 
cover the cost of HTpA activities. We recognize this may be different in other countries. However, we believe this is an optimal model ensuring transparency and addressing concerns with conflicts of interest.

- Reallocation of resources

The Guideline recommends that, whenever possible, it should be stated where and when the resources raised by disinvestment will be reinvested, which preferably should be for treatments in the same disease area. This should enhance the acceptability of the findings among key stakeholder groups.

\subsection{Guideline adjustments and approval of the final version by CONITEC/Brazil and the Ministry of Health.}

After presentation of the remarks to the Public Consultation and how these were addressed, the final version of the Guideline was accepted in the plenary of the CONITEC and sent for approval of the Minister of Health. The approval by the Brazilian Ministry of Health of the Guideline for Heath Technology performance Assessment was published on December 2nd 2016, and is now being taken forward. We will be assessing its impact in the future to determine whether there should be any revisions to the approved Guideline.

\section{CONCLUSION}

The development of the guideline has been an interactive process involving key personnel within Brazil and international participants. During its development, we started from the narrow objective of evaluating disinvestment to a wider objective of institutionalizing the continuous monitoring of funded health technologies in routine clinical care. We believe this has been a benefit to all stakeholders concerned. The adoption of the new concept - Health Technology performance Assessment - makes a distinction between the HTA activities for incorporation, which typically only consider controlled studies conducted by the producer for licensing and incorporation, and from Health Technology Reassessment, which does not necessarily incorporate real-world evidence.

Institutionalization of HTpA has the potential to continuously improve clinical guidelines to offer the best care to patients. In doing so, it may fulfil another important objective: the optimal reallocation of health resources - reinvestment, for the benefit of the society. It is clear that since neglecting care must be firmly avoided, reallocation of resources is automatic. Patients previously treated with the disinvested technology will be treated with other more efficient options. In the case of therapeutically equivalent generics and biosimilars, the resources released can be used to finance the increased demand for healthcare (28).

Alongside long-term real-world setting evaluations, it is urgent that RCTs conducted for licensing and funding assessments be improved. This could be achieved through the choice of more pragmatic and meaningful clinical outcome measures (10) and use of a gold-standard treatments as control. Both measures may go against the financial interests of companies, but may be 
implemented with stronger regulations by agencies worldwide. Technologies incorporated with stronger and credible evidence including outcomes as opposed to surrogate measures, and with a justifiable cost, may have the lowest possible chance of ever be indicated or prioritized for HTpA.

$\mathrm{HTpA}$ conducted right from funding decisions may be concurrent with conditional reimbursement schemes or managed entry arrangements, both of them conducted when there are concerns regarding value for money. Performance assessment adds to these concepts as it is a continuous task, reaching longer periods of evaluation and aiming to regularly update clinical guidelines. Performance assessment can include comparison with different treatment approaches with the rise in electronic health records and other systems to link databases together to assess their effectiveness and safety in routine clinical care.

Two important aspects that can complicate HTpA adoption are the additional costs required and the need for more robust administrative and/or clinical data collection and storage. Costs involved in HTpA can be seen as an investment to achieve better health care; nevertheless, immediate financial resources need to be allocated to improve or create relevant IT systems. In Brazil, the law guarantees investment in research related to the public health system, and we believe that part of this resource can be allocated to HTpA. Another option valid across countries are arrangements with the companies and the creation of research funds. The publication of this Guideline, along with the creation of a specific program for HTpA, will allow the institutionalization and continuous improvement of the scientific methods to collect real world evidence towards optimization of available resources. Disinvestment per se is one of the consequences of HTpA. The institutionalization of HTpA will encourage companies to adopt practices to improve quality use of their technologies to ensure their effectiveness and cost-effectiveness, favoring patients and the health system as a whole.

\section{REFERENCES}

1. Paris V, Belloni A. Value in Pharmaceutical Pricing: OECD Health Working Papers, No. 63: OECD Publishing; 2013. Available from: http://dx.doi.org/10.1787/5k43jc9v6knx-en]. [Accessed October 15, 2015].

2. Barnieh L, Manns B, Harris A, Blom M, Donaldson C, Klarenbach S, et al. A synthesis of drug reimbursement decision-making processes in organisation for economic co-operation and development countries. Value Health. 2014;17(1):98-108.

3. Tugwell P, Knottnerus JA. Is the 'Evidence-Pyramid' now dead? J Clin Epidemiol. 2015;68(11):1247-50.

4. Malmstrom RE, Godman BB, Diogene E, Baumgartel C, Bennie M, Bishop I, et al. Dabigatran - a case history demonstrating the need for comprehensive approaches to optimize the use of new drugs. Front Pharmacol. 2013;4:39.

5. Gold R, Kappos L, Arnold DL, Bar-Or A, Giovannoni G, Selmaj K, et al. Placebo-controlled phase 3 study of oral BG-12 for relapsing multiple sclerosis. N Engl J Med. 2012;367(12):1098-107. 
6. Joppi R, Cinconze E, Mezzalira L, Pase D, Poggiani C, Rossi E, et al. Hospitalized patients with atrial fibrillation compared to those included in recent trials on novel oral anticoagulants: a population-based study. Eur. J. Intern. Med. 2013;24(4):318-23.

7. Divittorio G, Jackson KL, Chindalore VL, Welker W, Walker JB. Examining the relationship between bone mineral density and fracture risk reduction during pharmacologic treatment of osteoporosis. Pharmacother. 2006;26(1):104-14.

8. Prasad V, Kim C, Burotto M, Vandross A. The Strength of Association Between Surrogate End Points and Survival in Oncology: A Systematic Review of Trial-Level Meta-analyses. JAMA Intern Med. 2015;175(8):1389-98.

9. Svensson S, Menkes DB, Lexchin J. Surrogate outcomes in clinical trials: a cautionary tale. JAMA Intern Med. 2013;173(8):611-2.

10. Henshall C SL, Eichler H-G, Lemgruber A, Longson C, O'Rourke B, Tunis S. Understanding the Role and Evidence Expectations of Health Technology Assessment and Coverage/Payer Bodies: What Are They Looking for, and How and Why Does This Differ From What Regulators Require? Ther. Innov. Regul. Sci. 2014;48 (3):341-46.

11. Downing NS, Aminawung JA, Shah ND, Krumholz HM, Ross JS. Clinical trial evidence supporting FDA approval of novel therapeutic agents, 2005-2012. JAMA. 2014;311(4):368-77.

12. Avorn J, Kesselheim AS. The 21st Century Cures Act--Will It Take Us Back in Time? N Engl J Med. 2015;372(26):2473-5.

13. Anderson ML, Chiswell K, Peterson ED, Tasneem A, Topping J, Califf RM. Compliance with results reporting at ClinicalTrials.gov. N Engl J Med. 2015;372(11):1031-9.

14. Gafni A, Birch S. Incremental cost-effectiveness ratios (ICERs): the silence of the lambda. Soc Sci Med. 2006;62(9):2091-100.

15. McCabe C, Claxton K, Culyer AJ. The NICE cost-effectiveness threshold: what it is and what that means. PharmacoEconomics. 2008;26(9):733-44.

16. Howard DH, Bach P, Berndt ER, Conti RM. Pricing in the Market for Anticancer Drugs. J. Econ. Perspect. 2015;29(1):139-62.

17. Simoens S, Picavet E, Dooms M, Cassiman D, Morel T. Cost-effectiveness assessment of orphan drugs: a scientific and political conundrum. Applied health economics and health policy. 2013;11(1):1-3.

18. Raftery JP. NICE's Cost-Effectiveness Range: Should it be Lowered? PharmacoEconomics. 2014;32(7):613-5. 
19. Ferrario A, Kanavos P. Managed entry agreements for pharmaceuticals: the European experience. London School of Economics and Political Science. 2013;154. Available from: http://eprints.Ise.ac.uk/50513/ [Accessed November 1, 2016].

20. Caires de Souza AL, de Assis Acurcio F, Guerra Junior AA, Rezende Macedo do Nascimento RC, Godman B, Diniz LM. Insulin glargine in a Brazilian state: should the government disinvest? An assessment based on a systematic review. Appl Health Econ Health Policy. 2014;12(1):19-32.

21. Gomes RM, Guerra Júnior AA, Lemos LL, Costa JeO, Almeida AM, Alvares J, et al. Tenyear kidney transplant survival of cyclosporine- or tacrolimus-treated patients in Brazil. Expert Rev Clin Pharmacol. 2016;9(7):991-9.

22. Raaschou P, Simard JF, Holmqvist M, Askling J, Group AS. Rheumatoid arthritis, antitumour necrosis factor therapy, and risk of malignant melanoma: nationwide population based prospective cohort study from Sweden. BMJ. 2013;346:f1939.

23. Costa J de O, Almeida-Brasil CC, Godman B, Fischer MA, Dartnell J, Heaney A, dos Santos CGB, Acúrcio F deA, Álvares J, Guerra Jnr AA. Implementation of clinical guidelines in Brazil: Should academic detailing be used? JPHS 2016;7:105-15.

24. Daniels T, Williams I, Robinson S, Spence K. Tackling disinvestment in health care services. The views of resource allocators in the English NHS. J Health Organ Manag. 2013;27(6):762-80.

25. Frønsdal KB, Facey K, Klemp M, Norderhaug IN, Mørland B, Røttingen JA. Health technology assessment to optimize health technology utilization: using implementation initiatives and monitoring processes. Int J Technol Assess Health Care. 2010;26(3):309-16.

26. Elshaug AG, Moss JR, Littlejohns P, Karnon J, Merlin TL, Hiller JE. Identifying existing health care services that do not provide value for money. Med J Aust. 2009;190(5):269-73.

27. Husereau D, Boucher M, Noorani H. Priority setting for health technology assessment at CADTH. Int J Technol Assess Health Care. 2010;26(3):341-7.

28. Parkinson B, Sermet C, Clement F, Crausaz S, Godman B, Garner S, et al. Disinvestment and Value-Based Purchasing Strategies for Pharmaceuticals: An International Review.

PharmacoEconomics. 2015;33(9):905-24.

29. Ford I, Murray H, McCowan C, Packard CJ. Long-Term Safety and Efficacy of Lowering LowDensity Lipoprotein Cholesterol With Statin Therapy: 20-Year Follow-Up of West of Scotland Coronary Prevention Study. Circulation. 2016;133(11):1073-80 